\title{
Effect of Changing Solvents on Poly( $\varepsilon$-Caprolactone) Nanofibrous Webs Morphology
}

\author{
A. Gholipour Kanani and S. Hajir Bahrami \\ Textile Engineering Department, Amirkabir University of Technology, Tehran 15875-4413, Iran \\ Correspondence should be addressed to S. Hajir Bahrami, hajirb@aut.ac.ir
}

Received 16 February 2011; Revised 6 April 2011; Accepted 6 April 2011

Academic Editor: Christian Brosseau

Copyright ( 2011 A. Gholipour Kanani and S. H. Bahrami. This is an open access article distributed under the Creative Commons Attribution License, which permits unrestricted use, distribution, and reproduction in any medium, provided the original work is properly cited.

\begin{abstract}
Polycaprolactone nanofibers were prepared using five different solvents (glacial acetic acid, 90\% acetic acid, methylene chloride/DMF 4/1, glacial formic acid, and formic acid/acetone 4/1) by electrospinning process. The effect of solution concentrations (5\%,10\%,15\% and 20\%) and applied voltages during spinning (10 KV to $20 \mathrm{KV}$ ) on the nanofibers formation, morphology, and structure were investigated. SEM micrographs showed successful production of PCL nanofibers with different solvents. With increasing the polymer concentration, the average diameter of nanofibers increases. In glacial acetic acid solvent, above $15 \%$ concentration bimodal web without beads was obtained. In MC/DMF beads was observed only at 5\% solution concentration. However, in glacial formic acid a uniform web without beads were obtained above $10 \%$ and the nanofibers were brittle. In formic acid/acetone solution the PCL web formed showed lots of beads along with fine fibers. Increasing applied voltage resulted in fibers with larger diameter.
\end{abstract}

\section{Introduction}

Nanomaterials such as nanoparticles, nanotubes, nanofibers, nanorods, and so forth, have been fabricated using numerous top-down and bottom-up nanofabrication technologies (such as electrospinning, phase separation, self-assembly processes, thin film deposition, chemical vapor deposition, chemical etching, nanoimprinting, photolithography, etc.) with ordered or random nanotopographies [1].

Electrospinning is a direct extension of the electrospraying phenomenon, as both processes are based on the same physical and electrical mechanisms. The main difference between the two is that electrospraying produces small droplets whereas electrospinning produces continuous fibers. In electrospinning, polymer nanofibers are formed by the creation and elongation of an electrified fluid jet [2-5]. In this technique the drawing is a process similar to dry spinning, which can make one-by-one very long single nanofibers. Only a viscoelastic material can be made into nanofibers through drawing. Phase separation method takes relatively long period of time to transfer the polymer into the nanoporous material. Similarly to the phase separation the self-assembly is time-consuming in processing continuous polymer nanofibers. Thus, the electrospinning process seems to be the only method which can be further developed for mass production of one-by-one continuous nanofibers from various polymers $[6,7]$.

The most commonly used biopolymers for nanofiber production are biodegradable poly ( $\alpha$-hydroxy ester) based polymer family such as poly(lactic acid) PLA, poly(glycolic acid) (PGA), poly ( $\varepsilon$-caprolactone) (PCL), and their copolymers. PCL is a semi crystalline linear hydrophobic polymer. This biodegradable material finds many applications in biomedical science owing to its superior mechanical properties, good biocompatibility, and complete degradation to nontoxic by-products $[8,9]$. It also has been used for improving elasticity because of its crystalline rubbery property [10]. Most synthetic polymers show slower degradation rates than natural biopolymers, because of their semi crystalline nature. PCL has the slower erosion rate of nanofiber matrices among the well-known biodegradable polyesters such as PGA, PLGA, and PLA. This fact is due to presence of five hydrophobic $-\mathrm{CH}_{2}$ moieties in its repeating units $[11,12]$. 
Numerous reports on the production of PCL nanofibers are available in the literature. Effect of three different solvent (methylene chloride (MC), MC/DMF, and MC/toluene) on physical and mechanical properties of PCL nonwoven mats produced by electrospinning was reported by Lee et al. [10]. It is reported that for the MC as a single solvent, electrospun fibers had very regular diameter of about $5500 \mathrm{~nm}$, but electrospinning was not facilitated, for the solvent system of MC/DMF, electrospinnability was enhanced and fiber diameter decreased with increasing DMF volume fraction. In $\mathrm{MC} /$ toluene system, with increasing toluene volume fraction, electrospinning is strictly restricted due to very high viscosity and low conductivity.

Beachley and Wen [13] reported the production of PCL electrospun nanofibers across two parallel plates for creating linearly oriented individual nanofiber arrays to investigate the nanofibers length. They explored the effect of electrospinning parameters such as solution concentration, plate size and applied voltage on the PCL nanofibers diameter and length [13]. They showed that relatively long continuous polycaprolactone (PCL) nanofibers with average diameters from approximately $350 \mathrm{~nm}$ to $1 \mu \mathrm{m}$ could be collected across parallel plates at lengths up to $35-50 \mathrm{~cm}$. The effect of changing the applied voltage, flow rate, distance between needle, and collector on electrospun webs were investigated on the PCL microfiber and multilayer nanofiber/microfiber scaffolds [14]. Effect of nanofibers diameter on the mechanical properties of web has been reported. Baji et al. [15] critically reviewed and evaluated the role of the microstructures on the fiber deformation behavior and presented possible explanations for the enhanced properties of the nanofibers. It was found that both modulus and strength of poly $(\varepsilon-$ caprolactone) (PCL) fibers were increased significantly when the diameter of the fibers was reduced to below $\sim 500 \mathrm{~nm}$ [15]. In another work, electrospun nanofibers and films of PCL-grafted dextran (PGD) were prepared by electrospinning and solvent evaporation methods, respectively. The authors concluded that the selected polymer enabled the fabrication of nanofibers of an average diameter $412 \mathrm{~nm}$ and there was slight increase in the crystallization temperature along with linear increase in heat of fusion in both fibers and films during the progress of hydrolysis [15].

In the present work, effect of different solvents, that is, glacial acetic acid, $90 \%$ acetic acid, methylene chloride/dimethyl formamide (MC/DMF) (4/1), glacial formic acid and formic acid/acetone (4/1) on nanofibrous web morphology, beads formation, and fibers diameters, has been reported for the first time. Polymer solutions in the above solvents with different concentration (5-20\%) were used for nanofibers production and their effects on the fiber structure were investigated. Applied voltage varied from 10 to $20 \mathrm{KV}$ to study the effect on the spinnability and diameter of the produced nanofibers. SEM micrographs were used to investigate the nanofibers and beads morphology.

\section{Materials and Methods}

PCL (Mw $80 \mathrm{KDa}$ ) were purchase from Sigma-Aldrich. Glacial acetic acid, glacial formic acid, methylene chloride, and dimethyl formamide (DMF) were purchased from Merck Co. and used without any purification.

2.1. Preparing the Solutions. In order to investigate the solvents type and polymer concentration effects on the formation and morphology of nanofibers, polymer solution in five different solvents with different concentration, that is, $5 \%, 10 \%, 15 \%$, and $20 \%$ were prepared. Solutions were prepared by dissolving PCL in each of the five solvents and stirred for $24 \mathrm{~h}$ at room temperature.

2.2. Electrospinning Process. Briefly, polycaprolactone (PCL) solutions were placed in a $20 \mathrm{~mL}$ syringe. During the electrospinning process, feeding rate and distance between needle and collector were fixed at $0.5 \mathrm{~mL} / \mathrm{h}$ and $20 \mathrm{~cm}$, respectively. Upon applying voltage 10,15 and $20 \mathrm{kv}$ using a high-voltage power supply (Gamma high-voltage research), a fluid jet was ejected from the tip of the needle. The jet extends in a straight line for a certain distance and then bends and follows a looping and spiraling path. As the jet accelerated toward the target, the solvent evaporated and polymer nanofibers were collected on $10 \mathrm{~cm} \times 10 \mathrm{~cm}$ aluminum foil. All electrospinning were carried out at room temperature.

2.3. Nanofibers Morphology Studies. Electrospun PCL mats were coated with gold and observed by scanning electron microscopy (SEM; Philips XL30). For quantification of fiber diameters, measurements were made on 20 random locations of the nanofibers using Image J software, and the average of these twenty measurements was used as an average diameter of these nanofibers. The viscosity of the polymer solutions was measured using a Brookfield viscometer (Model DVII + Pro). For conductivity measurements, $10 \mathrm{~mL}$ of each solution was taken in a plastic container and conductivity was measured using EUTECH COND 610 conductivity meter at $22^{\circ} \mathrm{C}$.

\section{Results and Discussion}

3.1. The Effects of Different Solvents. Five different solvents, that is, Glacial acetic acid (GAA), 90\% acetic acid (90AA), Methylene chloride/dimethyl formamide (MC/DMF) 4/1, glacial formic acid (GFA), and formic acid/acetone (FA/AC) were used to prepare PCL solutions. In electrospinning technique, the ejected charged jet is affected by electrical forces, so it needs to have high electrical properties such as good dielectric constant to enhance the density of charges at the surface of jet for better stretching and uniform formation of fibers with proper morphology. Since, PCL is a hydrophobic and linear semi crystalline polymer, organic solvents such as acetic acid, formic acid, methylene chloride, and so forth, can be used as solvent. However, solubility is not the only criteria for nanofiber formation from a polymer solution. For instance, Methylen chloride (MC) is a common solvent for PCL, but because of its moderate dielectric constant, it is not suitable for electrospinning process. PCL solution prepared in MC cannot be converted 


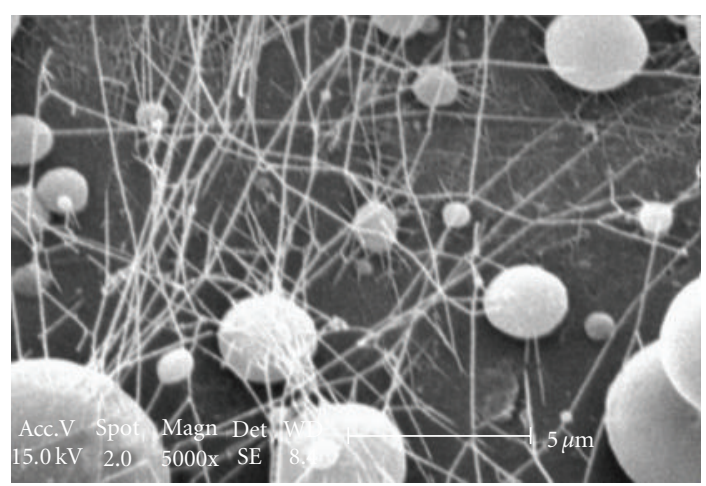

(a)

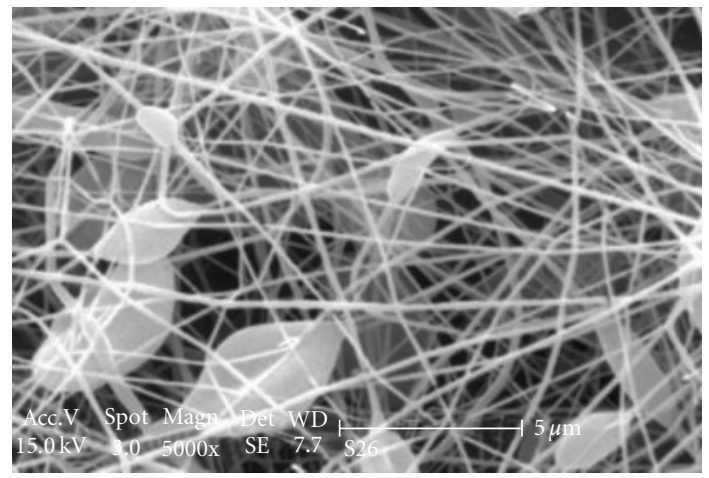

(c)

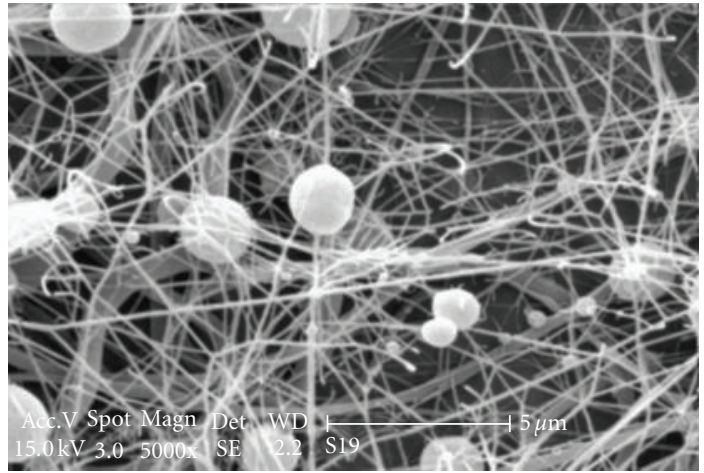

(b)

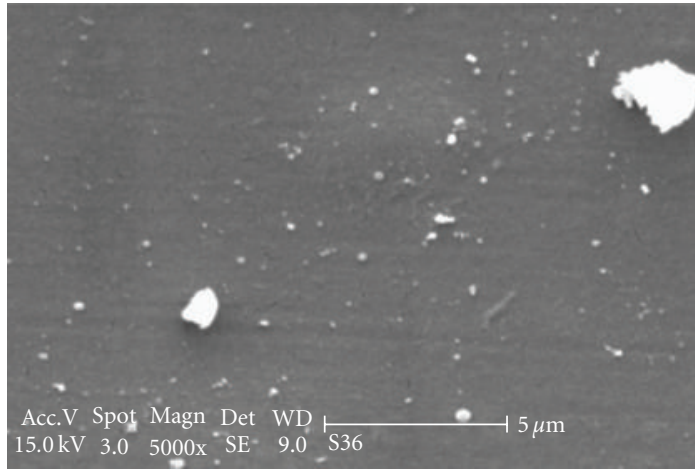

(d)

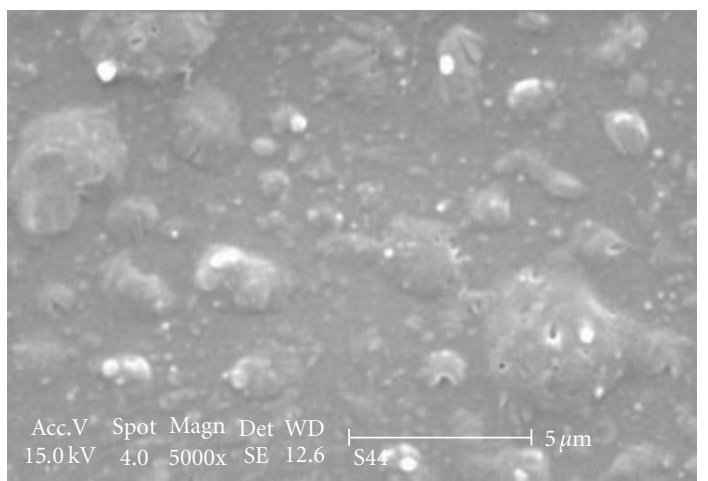

(e)

FIGURE 1: Electrospun resulted SEM micrographs of PCL 5\% solutions dissolved in different solvents: (a) glacial acetic acid, (b) $90 \%$ acetic acid, (c) methylen chloride/ DMF = 4/1, (d) glacial formic acid, (e) formic acid/acetone = 4/1; (Voltage: $15 \mathrm{KV}$, distance: $20 \mathrm{~cm}$, and extrusion rate: $0.5 \mathrm{~mL} / \mathrm{hr}) ; 5000 \mathrm{x}$.

into nanofibers with good morphology, but when DMF is added and MC/DMF is used as solvent system, spinning process is enhanced and uniform fibers can be obtained. Lee et al. [10] reported that the best ratio of this solvent system for obtaining fibers with uniform morphology is MC/DMF $80 / 20$.

A glacial acetic acid dissolves PCL and nanofibers with different morphology can be obtained by varying electrospinning parameters and polymer concentrations. When water is added to acetic acid, its effect is similar to DMF for MC. Due to nonsolvent effect of water in PCL solutions, the amount of water is critical in the solvent system and it was found that $90 \%$ acetic acid was optimum ratio for obtaining fibers with uniform morphology. Formic acid was used for the first time in this study and formic acid/acetone was used based on work reported in [16]. Malheiro et al. [16] used this solvent for wet spinning of PCL and PCL-chitosan blend fibers.

The electrospinning process was carried out under the following conditions: the applied voltage was $15 \mathrm{KV}$, solution concentration was $5 \%$, nozzle to collector distance was $20 \mathrm{~cm}$ and extrusion rate of polymer solution was adjusted in $0.5 \mathrm{~mL} / \mathrm{hr}$.

When glacial acetic acid was used as solvent, many microsphere-shaped beads and few fine fibers were detected in SEM micrographs (Figure 1(a)). On the other hand, when 
TABLE 1: Effect of different solvents on nanofibrous web morphology (10\% PCL, $V=15 \mathrm{KV}, D=20 \mathrm{~cm}$, and $R=0.5 \mathrm{~mL} / \mathrm{hr})$.

\begin{tabular}{|c|c|c|c|c|c|c|c|}
\hline \multirow[b]{2}{*}{$\begin{array}{l}\text { Solvent } \\
\text { type }\end{array}$} & \multirow[b]{2}{*}{$\begin{array}{l}\text { Nanofibers } \\
\text { morphology }\end{array}$} & \multirow[b]{2}{*}{ Beads type } & \multirow[b]{2}{*}{$\begin{array}{l}\text { Viscosity } \\
\text { (cPs) }\end{array}$} & \multirow[b]{2}{*}{$\begin{array}{l}\text { Nanofibers average } \\
\text { diameter }\end{array}$} & \multirow{2}{*}{$\begin{array}{l}\text { Solution } \\
\text { conductivity } \\
(\mathrm{mS} / \mathrm{m})\end{array}$} & \multicolumn{2}{|c|}{ Beads size $(\mu \mathrm{m})$} \\
\hline & & & & & & $(\mathrm{a})^{* *}$ & $\overbrace{}^{(\mathrm{b})^{* *}}$ \\
\hline GAA & Good & Spindle-like & 25 & $112 \pm 32 \mathrm{~nm}$ & 0.025 & $1.9 \pm 0.4$ & $3.8 \pm 0.9$ \\
\hline $90 \mathrm{AA}$ & Good & Spindle-like & 28.5 & $147 \pm 48 \mathrm{~nm}$ & 0.04 & $0.22 \pm 0.14$ & $0.6 \pm 0.1$ \\
\hline $\begin{array}{l}\text { MC/DMF } \\
(4 / 1)\end{array}$ & $\begin{array}{l}\text { Good: bimodal* } \\
\text { morphology }\end{array}$ & No beads & 31.5 & $603 \pm 308 \mathrm{~nm}$ & 0.06 & - & - \\
\hline GFA & $\begin{array}{l}\text { Bad: very brittle } \\
\text { fibers with some } \\
\text { branches }\end{array}$ & No beads & 10 & $146 \pm 24 \mathrm{~nm}$ & 0.037 & - & - \\
\hline $\begin{array}{l}\text { FA/acetone } \\
(4 / 1)\end{array}$ & $\begin{array}{l}\text { Bad: branchy fibers } \\
\text { with a lot of beads }\end{array}$ & $\begin{array}{l}\text { Sphere-shape } \\
\text { beads }\end{array}$ & 9.5 & $100 \pm 23 \mathrm{~nm}$ & 0.036 & - & - \\
\hline
\end{tabular}

${ }^{*}$ :Blend of two different type of sizes (microfibers and nanofibers).

**:(a) Beads average height, (b) beads average length.

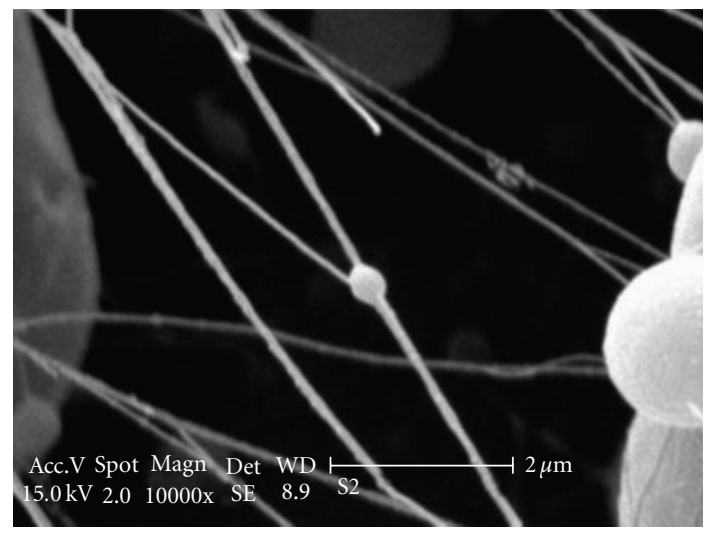

(a)

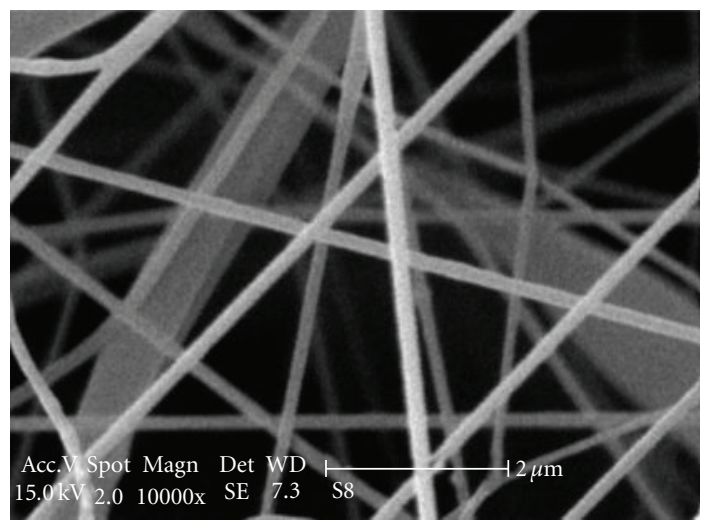

(c)

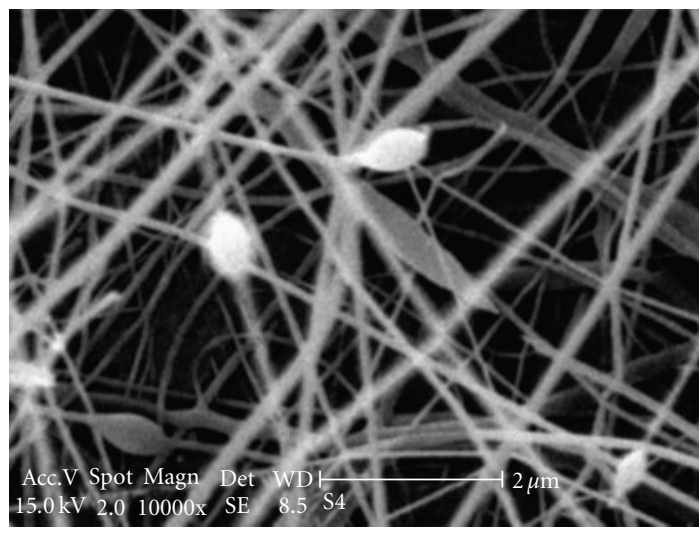

(b)

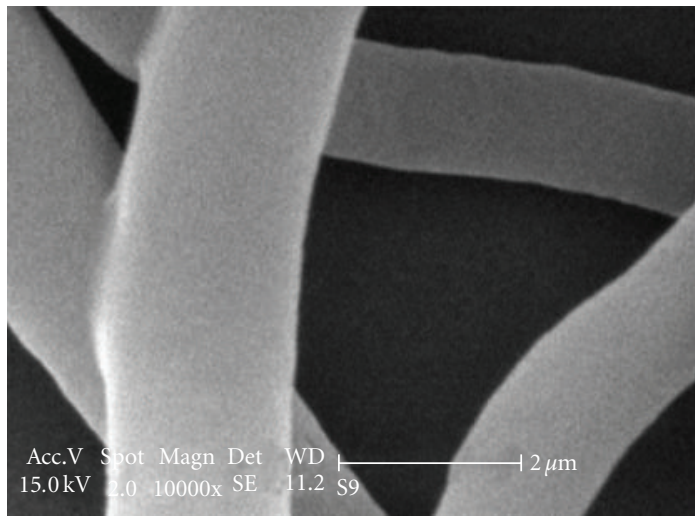

(d)

FIGURE 2: Nanofibers SEM micrographs from PCL dissolved in glacial acetic acid in different concentrations: (a) 5\%, (b) 10\%, (c) 15\%, and (d) $20 \%$; (voltage: $15 \mathrm{KV}$, distance: $20 \mathrm{~cm}$, and extrusion rate: $0.5 \mathrm{~mL} / \mathrm{hr}$ ); $10000 \mathrm{x}$.

the solvent was changed to $90 \%$ acetic acid, there were still a lot of microsphere beads with smaller size accompanied with more fibers of fine diameters $(81.5 \pm 8 \mathrm{~nm}$ average diameter; Figure 1(b)). It seems that adding water to acetic acid enhanced the electrospinnability of PCL solutions by changing electrical properties of solution.

Spindle-like-shaped beads near to a lot of nanofibers were observed when the solvent was MC/DMF, but the aver- age diameter was about two-times thicker than the nanofibers average diameters that fabricated with the two former solvents (Figure 1(c)). This fact is due to different viscosities of polymer solutions made by different solvents at the same concentration. In comparison with three former solvents, when PCL was dissolved in glacial formic acid and solvent system formic acid/acetone $4 / 1$, no fibers were detected and only big droplets were formed on the collector (Figures 1(d) 


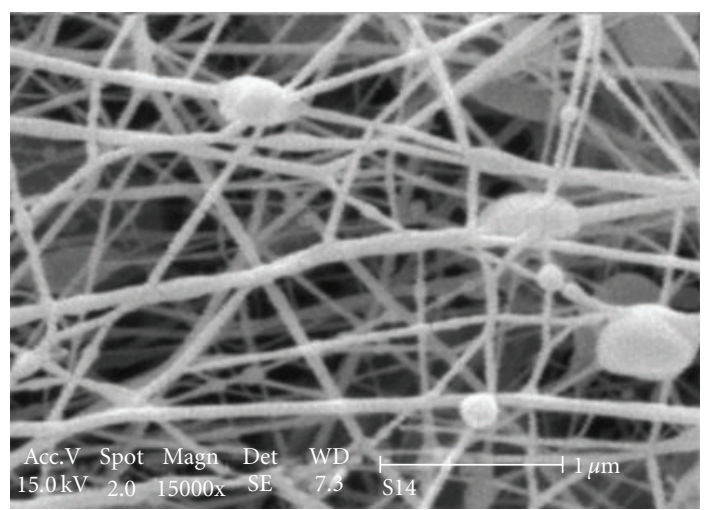

(a)

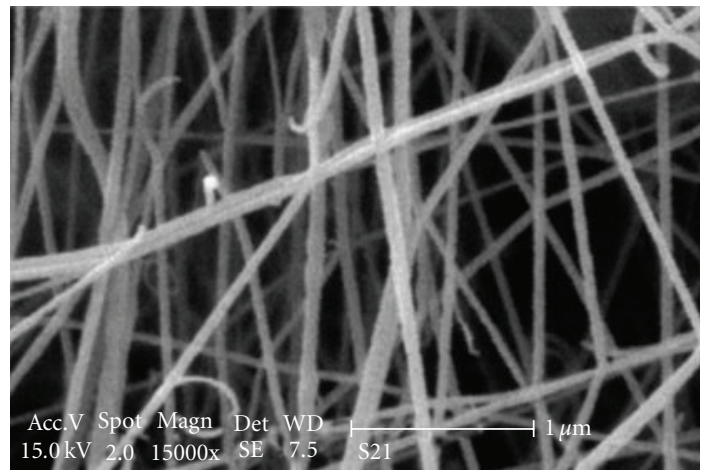

(c)

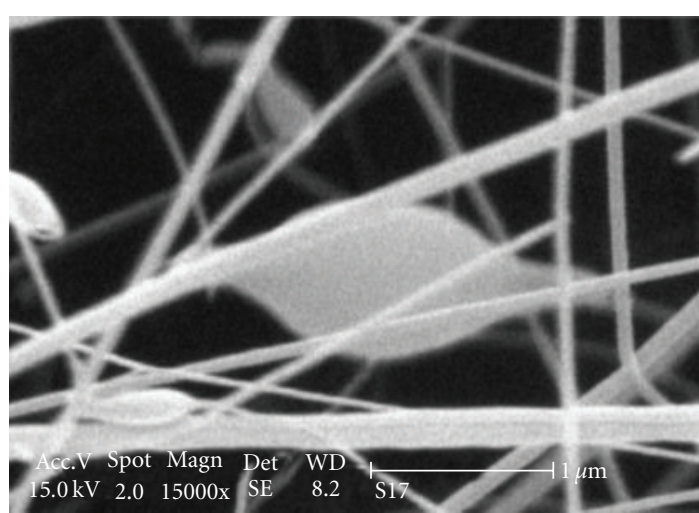

(b)

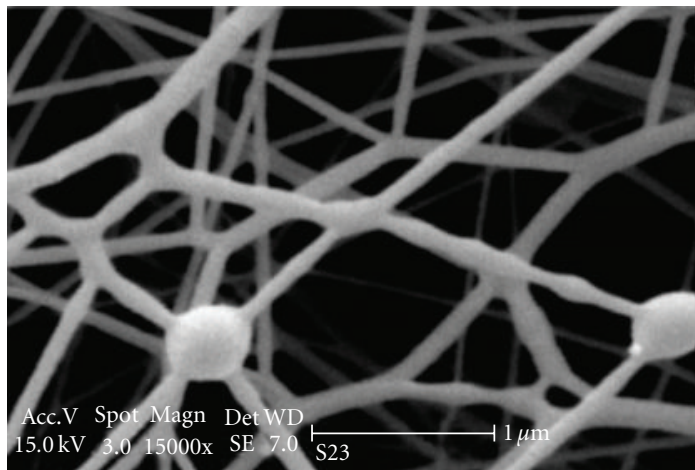

(d)

FIGURE 3: Nanofibers SEM micrographs from PCL dissolved in 90\% acetic acid in different concentrations: (a) 5\%, (b) $10 \%$, (c) $15 \%$, and (d) $20 \%$; (voltage: $15 \mathrm{KV}$, distance: $20 \mathrm{~cm}$, and extrusion rate: $0.5 \mathrm{~mL} / \mathrm{hr}$ ); $15000 \mathrm{x}$.

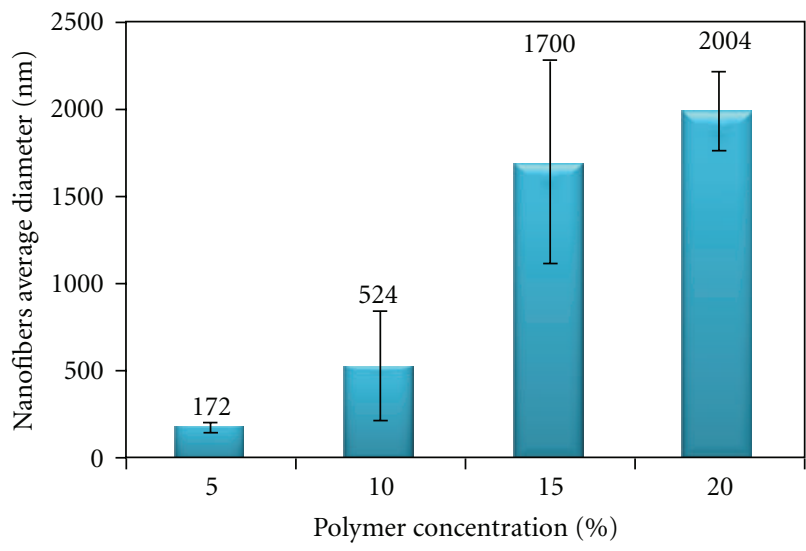

FIGURE 4: Nanofibers average diameter versus polymer concentration of PCL dissolved in MC/DMF (4/1), electrospun at voltage: $15 \mathrm{KV}$, distance: $20 \mathrm{~cm}$, and extrusion rate: $0.5 \mathrm{~mL} / \mathrm{hr}$.

and $1(\mathrm{e}))$. It was because of very low viscosities of $5 \%$ solutions in this solvent.

When solution concentration was increased to $10 \%$ the morphology of web and beads changed. Table 1 explains change in the morphology of electrospinning product in different solvent at $10 \%$ concentration.

The polymer solution viscosity is an important parameter which influences the spinnability. However, different polymers regardless of molecular weight have different spinnable viscosity ranges. As it is clear from Table 1, these solvents showed different solution viscosities at the same concentrations. By comparing the beads size it was found that by changing the solvents from glacial acetic acid to $90 \%$ acetic acid, the beads sizes decreased six times. Although for $10 \%$ PCL in glacial acetic acid the aspect ratio of (b/a) was about 2, the aspect ratio was larger than $2(\sim 2.7)$ for $10 \%$ PCL in $90 \%$ acetic acid, which shows that beads get more stretched while the viscosity increases from $25 \mathrm{cPs}$ to $28.5 \mathrm{cPs}$. This could be due to effect of water acting as nonsolvent which helps faster fibers solidification and produces fibers with larger diameters. On the other hand, water diffusion among polymer chains, may increase the hydrodynamic volume of the chain, and it causes more entanglement and results higher viscosity as it clear in Table 1.

3.2. The Effects of Solution Concentrations in Different Solvents. Polymer concentration is important parameter in the electrospinning process too. This fact is due to its strong relation with viscosity of the polymer. When different solvents are used to make polymer solutions with same concentration, different viscosities of polymer solutions are observed. The viscosity of polymer is affected by two different parameters (solvent type and polymer concentration). 
TABLE 2: Effect of different solvent and different applied voltage on average diameter.

\begin{tabular}{|c|c|c|c|}
\hline PCL concentration $(\%)$ & Solvent type & Applied voltage (KV) & Average diameter \\
\hline \multirow{15}{*}{5} & GAA & 10 & $82 \pm 8 \mathrm{~nm}$ \\
\hline & & 15 & $93 \pm 5 \mathrm{~nm}$ \\
\hline & & 20 & $102 \pm 8 \mathrm{~nm}$ \\
\hline & $90 \mathrm{AA}$ & 10 & $81.5 \pm 18 \mathrm{~nm}$ \\
\hline & & 15 & $112 \pm 33 \mathrm{~nm}$ \\
\hline & & 20 & $120 \pm 42 \mathrm{~nm}$ \\
\hline & $\mathrm{MC} / \mathrm{DMF} 4 / 1$ & 10 & $164 \pm 47 \mathrm{~nm}$ \\
\hline & & 15 & $172 \pm 30 \mathrm{~nm}$ \\
\hline & & 20 & $220 \pm 48 \mathrm{~nm}$ \\
\hline & GFA & 10 & Droplets \\
\hline & & 15 & Droplets \\
\hline & & 20 & Droplets \\
\hline & FA/AC $4 / 1$ & 10 & Droplets \\
\hline & & 15 & Droplets \\
\hline & & 20 & Droplets \\
\hline \multirow{15}{*}{10} & GAA & 10 & $112 \pm 32 \mathrm{~nm}$ \\
\hline & & 15 & $115 \pm 31 \mathrm{~nm}$ \\
\hline & & 20 & $138 \pm 70 \mathrm{~nm}$ \\
\hline & $90 \mathrm{AA}$ & 10 & $121 \pm 27 \mathrm{~nm}$ \\
\hline & & 15 & $147 \pm 48 \mathrm{~nm}$ \\
\hline & & 20 & $101 \pm 12 \mathrm{~nm}$ \\
\hline & MC/DMF 4/1 & 10 & $524 \pm 315 \mathrm{~nm}$ \\
\hline & & 15 & $603 \pm 308 \mathrm{~nm}$ \\
\hline & & 20 & $767 \pm 307 \mathrm{~nm}$ \\
\hline & GFA & 10 & $108 \pm 44 \mathrm{~nm}$ \\
\hline & & 15 & $146 \pm 24 \mathrm{~nm}$ \\
\hline & & 20 & $148 \pm 19 \mathrm{~nm}$ \\
\hline & FA/AC $4 / 1$ & 10 & $81 \pm 10 \mathrm{~nm}$ \\
\hline & & 15 & $100 \pm 23 \mathrm{~nm}$ \\
\hline & & 20 & $106 \pm 27 \mathrm{~nm}$ \\
\hline \multirow{15}{*}{15} & GAA & 10 & $296 \pm 76 \mathrm{~nm}$ \\
\hline & & 15 & $325 \pm 181 \mathrm{~nm}$ \\
\hline & & 20 & $300 \pm 205 \mathrm{~nm}$ \\
\hline & $90 \mathrm{AA}$ & 10 & $144 \pm 56 \mathrm{~nm}$ \\
\hline & & 15 & $117 \pm 30 \mathrm{~nm}$ \\
\hline & & 20 & $159 \pm 61 \mathrm{~nm}$ \\
\hline & MC/DMF 4/1 & 10 & $528 \pm 117 \mathrm{~nm}$ \\
\hline & & 15 & $1.5-2 \mu \mathrm{m}$ \\
\hline & & 20 & $2-2.5 \mu \mathrm{m}$ \\
\hline & GFA & 10 & $308 \pm 32 \mathrm{~nm}$ \\
\hline & & 15 & $316 \pm 39 \mathrm{~nm}$ \\
\hline & & 20 & $320 \pm 23 \mathrm{~nm}$ \\
\hline & FA/AC $4 / 1$ & 10 & $150 \pm 21 \mathrm{~nm}$ \\
\hline & & 15 & $161 \pm 17 \mathrm{~nm}$ \\
\hline & & 20 & $169 \pm 23 \mathrm{~nm}$ \\
\hline
\end{tabular}


TABle 2: Continued.

\begin{tabular}{lccc}
\hline PCL concentration (\%) & Solvent type & Applied voltage (KV) & Average diameter \\
\hline & GAA & 10 & $1-2 \mu \mathrm{m}$ \\
& 15 & $2.5-3 \mu \mathrm{m}$ \\
& 20 & $2.5-3 \mu \mathrm{m}$ \\
90AA & 10 & $186 \pm 86 \mathrm{~nm}$ \\
& 15 & $194 \pm 56 \mathrm{~nm}$ \\
& 20 & $185 \pm 20 \mathrm{~nm}$ \\
MC/DMF 4/1 & 10 & $1.6-2.3 \mu \mathrm{m}$ \\
& 15 & $1.8-2.3 \mu \mathrm{m}$ \\
& 20 & $2.7-3.3 \mu \mathrm{m}$ \\
GFA & 10 & $185 \pm 39 \mathrm{~nm}$ \\
& 15 & $88 \pm 25 \mathrm{~nm}$ \\
& 20 & $88 \pm 12 \mathrm{~nm}$ \\
FA/AC 4/1 & 10 & No distinguishable fibers \\
\hline
\end{tabular}

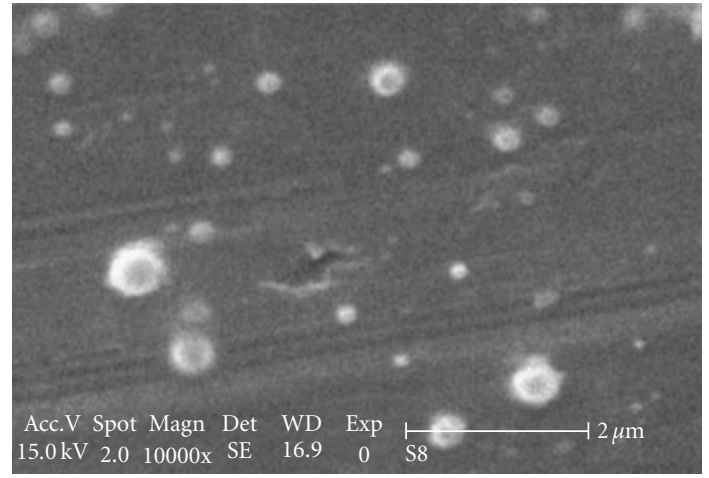

(a)

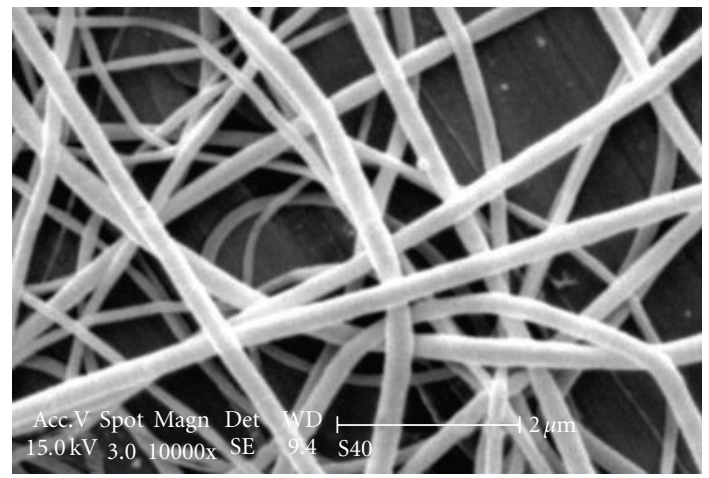

(c)

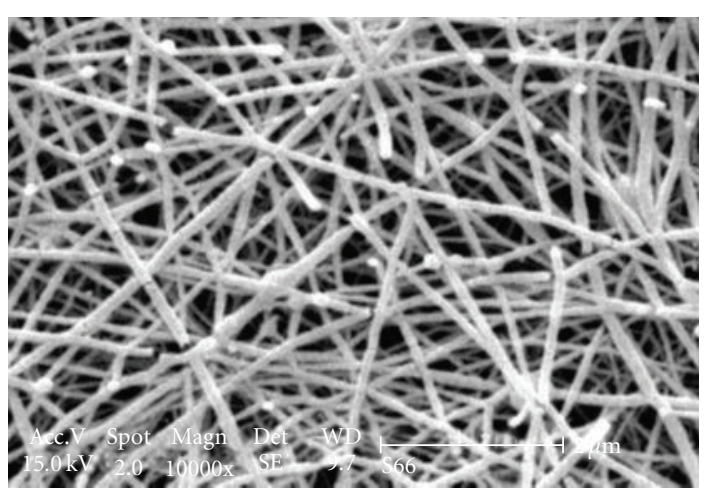

(b)

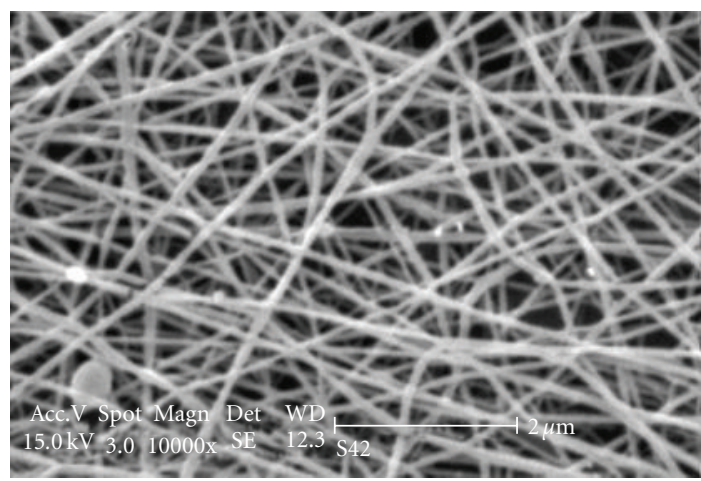

(d)

Figure 5: Nanofibers SEM micrographs from PCL dissolved in glacial formic acid in different concentrations: (a) 5\%, (b) 10\%, (c) 15\%, and (d) 20\%; (voltage: $15 \mathrm{KV}$, distance: $20 \mathrm{~cm}$, and extrusion rate: $0.5 \mathrm{~mL} / \mathrm{hr}$ ); $10000 \mathrm{x}$.

Liu and coworkers [17] showed that when the polymer concentration was low, many beads or droplets appeared in the poly(butylenes succinate) (PBS) nanofibrous webs, and the process converted to electrospraying when the concentration became low enough. In our study, when the concentration of polymer solution was $5 \%$ in glacial acetic acid for which the solution viscosity was not high, with applying voltage the jet get stretched very quickly because of low surface tension and fine fibers were formed. However, due to this applied voltage the polymer mass at the tip of the needle gets converted into fibers quickly and driven away from the tip of needle rapidly. Because of lack of enough chain entanglement uneven drawing of polymer mass takes place which results in formation of nanofibers and beads connected to them. Liu et 


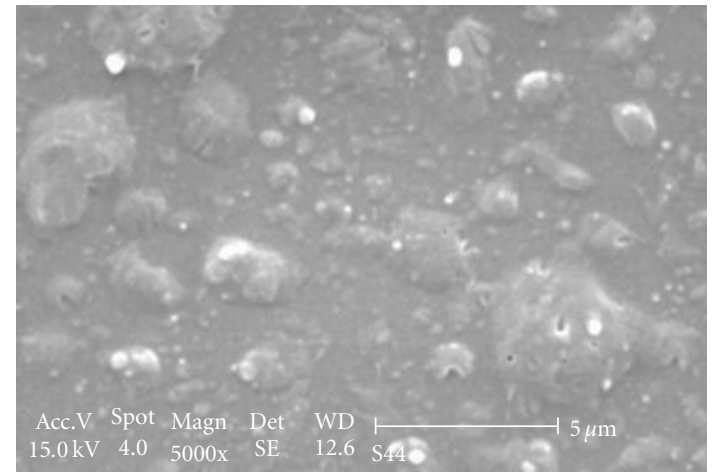

(a)

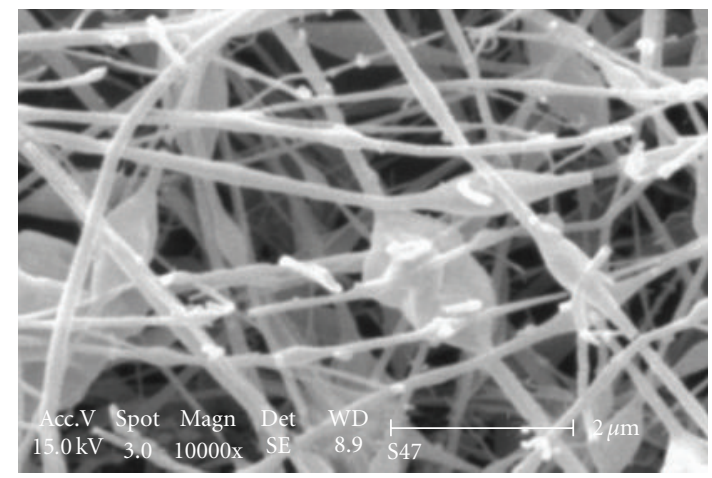

(c)

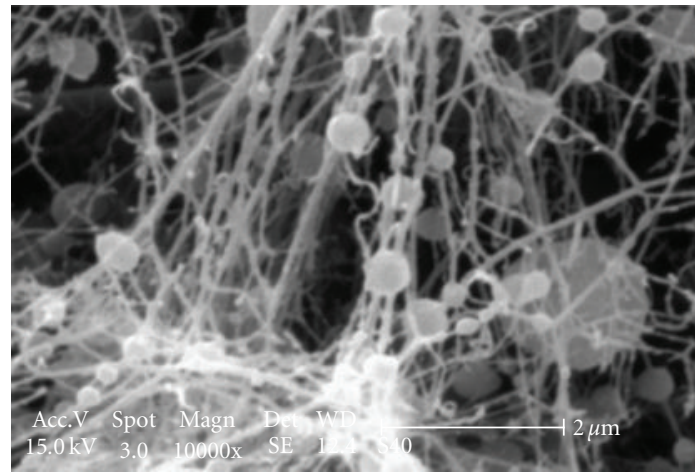

(b)

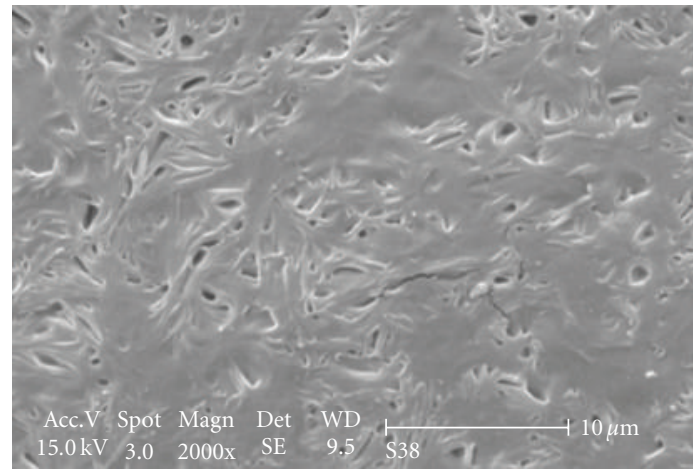

(d)

FigURE 6: Nanofibers SEM micrographs from PCL dissolved in formic acid/acetone 4/1 in different concentrations: (a) 5\% (5000x), (b) 10\% and (c) $15 \%$ (10000x), and (d) 20\% (2000x); (voltage: $15 \mathrm{KV}$, distance: $20 \mathrm{~cm}$, and extrusion rate: $0.5 \mathrm{~mL} / \mathrm{hr}$ ).

al. also showed that increasing the polymer concentration, decreases the number and size of beads, and eliminating beads completely in some cases $[17,18]$. This is due to the increased degree of chain entanglement, which is necessary for formation of continuous fibers. The concentration effects were investigated in each solvent. Samples prepared with the following conditions: $15 \mathrm{KV}$ applied voltage, $20 \mathrm{~cm}$ nozzle to collector distance, and $0.5 \mathrm{~mL} / \mathrm{hr}$ polymer extrusion rate.

3.2.1. Glacial Acetic Acid (GAA) as Solvent. When glacial acetic acid was used as solvent, at 5\% PCL concentration a lot of big sphere-shaped beads and little fibers were observed in SEM micrographs, as it was reported above (Figure 2(a)). By increasing the polymer concentration to $10 \%$, beads shapes were changed to nanoscale spindle-like, although the numbers of beads were high, the fibers morphology is developed and the average diameter increased to $115 \pm$ $31 \mathrm{~nm}$ (Figure 2(b)). It should be noted that by increasing the viscosity of solution, the average fiber diameter distribution was wide.

In Figure 2(c), the uniform fibers with no beads were detected when 15\% PCL in glacial acetic acid were electrospun, though the diameter distribution got much wider. It means that, there were some microscale fibers among a lot of nanofibers produced. Same trend is followed in 20\% PCL, and microscale fibers with 1-2 micrometer diameters were obtained (Figure 2(d)).

3.2.2. $90 \%$ Acetic Acid (90AA) as Solvent. A similar trend is followed for $90 \%$ acetic acid as a solvent in different concentrations. For 5\% PCL in 90\% acetic acid, microsphere beads near to a lot of fine fibers were found. By increasing the solution concentration to $10 \%$, spindle-like beads were recognized among a lot of fine nanofibers. By comparing the average diameter and diameter distribution among the different concentration, it was found that by increasing the concentration the distribution got wider. The number of beads gradually decreased with an increase of the polymer concentration from $5 \%$ to $15 \%$. At $20 \%$ solution concentration, nanofibers form a network structure in which beads are also present connecting different fibers in this network structure. However, the surfaces of fibers are not smooth.

\subsubsection{Methylene Chloride/Dimethyl Formamide (MC/DMF)} as Solvent. As it can be seen in Figure 1(c), the morphology of the web produced from MC/DMF solvent is better than the other webs at $5 \%$ concentrations. This could be due to higher viscosity of polymer solution in MC/DMF compare to others four solvents. When the concentration increased to $10 \%$ in MC/DMF more uniform nanofibers were produced and web bimodality increased. It means some micro-fibers 
were embedded in the nanofibrous webs. In the recent years, biomedical scientists have tried to reach bimodal morphology in biological scaffolds $[4,6,13-15]$. This is due to resemblance of bimodal nanofibrous webs to natural ECM (extracellular matrix) and its high biological effects in biomedical applications. Electrospinning of 20\% PCL solution resulted in microfibers of diameters in the range of $2000 \mathrm{~nm}$. Change in average diameter of fibers produced versus increasing the polymer concentration is shown in Figure 4.

3.2.4. Glacial Formic Acid (GFA) as Solvent. When glacial formic acid was used as solvent at 5\% concentration of PCL, solution could not be electrospun and process became electrospraying (Figure 5(a)). At 10\% concentration, solution could be electrospun and nanofibers with average diameter of $146 \pm 24 \mathrm{~nm}$ could be collected on the plate (Figure 5(b)). However, as it can be seen the nanofibers were brittle. This could be due to high volatilization rate of solvent and the low viscosity, and therefore polymer jet did not have enough chain entanglements and because of high speed of spinning, time was not sufficient for jet orientation before solvent evaporation. Nonbrittle uniform fibers with no beads were formed when the concentration increased to $15 \%$. Although, the fiber diameter became two-times thicker, the surface is much smoother and fibers are not broken (Figure 5(c)). Nanofibers with $88 \pm 25 \mathrm{~nm}$ average diameter were resulted when $20 \%$ PCL solution was electrospun. It showed web structure with narrow fibers diameters distribution (Figure 5(d)).

3.2.5. Formic Acid/Acetone (FA/AC) as Solvent. Due to low viscosity at $5 \%$ PCL, only the droplets were formed on the collecting plate (Figure 6(a)). A lot of nanoscale sphere-shaped bead near to branchy and fine fibers were detected while the polymer concentration reached to $10 \%$ (Figure 6(b)). By increasing the concentration to $15 \%$ more spindle-like beads were formed (Figure 6(c)). Changing the beads shape could be due to change in the viscosity of polymer, which resulted in web with better morphology at $15 \%$ concentration. At $20 \%$ concentration, it seems the solution viscosity was high and the distance of collector was not sufficient, therefore, the polymer jets collapsed on the collector plate without sufficient evaporation of solvent and formed more or less a nonuniform porous surface (Figure 6(d)).

3.3. Effect of Changing Voltage on Nanofibers Diameter. The results of PCL electrospinning in these solvents at different concentrations and voltages are summarized in Table 2. With increasing the concentration and applied voltage, generally the diameters of nanofibers increased.

Demir et al. suggested that when higher voltages are applied more polymer is ejected to form a larger diameter fiber [19]. Similarly, high-voltage conditions also created a rougher fiber structure. Similar resulted were obtained in our study.

In general, increasing the voltage increases the diameter of PCL nanofibers. However, this increase is not very significant in the case of 90AA PCL solutions and the variation in the nanofibers diameter indicates that these differences are not significant. Therefore, considering the variations reported for nanofibers diameters for 90AA electrospun at 10, 15 , and $20 \mathrm{KV}$ the fibers diameters are not significantly different. Another point which may be considered is the effect of water present in the solvent which may change the ionization behavior of the solution. With increasing the ionization of the solution the increase in the voltage may affect the fibers diameter in a different way.

\section{Conclusion}

When GAA was used as solvent, with increasing polymer concentration, the dispersity of the average diameter increased or nanofibers of nonuniform diameter were produced. However, when 90AA was used as solvent the fibers average diameter dispersity remained in the range of few tens of nanometers. For MC/DMF system, fibers produced had their diameters in the range of nano to micrometer which indicated production of bimodal web. At higher concentration of PCL in GFA nanofibers of uniform diameter dispersity were formed. Nanofibers with almost uniform diameters were produced at $10 \%$ and $15 \%$ PCL concentrations when FA/AC was used as solvent. With increasing polymer concentration, viscosity of polymer solution increased and spherical shape beads changed to spindlelike shape and with further increase in the concentration the beads vanished. For AA as solvent at 5\% PCL concentration, spherical beads formed which changed to spindle-like shape at $10 \%$ and vanished at $15 \%$ and $20 \%$ PCL concentrations. Same trend was observed for solutions in 90AA. At 5\% concentration in MC/DMF beads were present in the form of stretched spindle-like shape which disappeared at higher concentrations. By increasing the polymer concentration in each solvent, the average diameter of resulted fiber increased. The number of beads gradually decreased with increasing the polymer concentration from $5 \%$ to $20 \%$.

\section{References}

[1] L. Zhang and T. J. Webster, "Nanotechnology and nanomaterials: promises for improved tissue regeneration," Nano Today, vol. 4, no. 1, pp. 66-80, 2009.

[2] D. H. Reneker, A. L. Yarin, E. Zussman, and H. Xu, "Electrospinning of nanofibers from polymer solutions and melts," in Advances in Applied Mechanics, H. Aref and E. van der Giessen, Eds., vol. 41, p. 43e195, Elsevier/Academic Press, London, UK, 2007.

[3] D. H. Reneker and A. L. Yarin, "Electrospinning jets and polymer nanofibers," Polymer, vol. 49, no. 10, pp. 2387-2425, 2008.

[4] A. GholipourK, S. H. Bahrami, and M. Nouri, "Chitosanpoly(vinyl alcohol) blend nanofibers: morphology, biological and antimicrobial properties," E-Polymers, no. 33, pp. 1-12, 2009. 
[5] A. Gholipour, S. H. Bahrami, and M. Nouri, "Optimization of chitosan-polyvinylalcohol electrospinning process by Response Surface Methodology (RSM)," E-Polymers, no. 35, pp. 1-9, 2010.

[6] Z. M. Huang, Y. Z. Zhang, M. Kotaki, and S. Ramakrishna, "A review on polymer nanofibers by electrospinning and their applications in nanocomposites," Composites Science and Technology, vol. 63, no. 15, pp. 2223-2253, 2003.

[7] S. Ramakrishna, K. Fujihara, W. Teo, and Z. Ma, An Introduction to Electrospinning and Nanofibers, World Scientific, Singapore, 2005.

[8] X. Zong, S. Ran, K. S. Kim, D. Fang, B. S. Hsiao, and B. Chu, "Structure and morphology changes during in vitro degradation of electrospun poly(glycolide-co-lactide) nanofiber membrane," Biomacromolecules, vol. 4, no. 2, pp. 416-423, 2003.

[9] S. R. Bhattarai, N. Bhattarai, P. Viswanathamurthi, H. K. Yi, P. H. Hwang, and H. Y. Kim, "Hydrophilic nanofibrous structure of polylactide; fabrication and cell affinity," Journal of Biomedical Materials Research Part A, vol. 78, no. 2, pp. 247257, 2006.

[10] K. H. Lee, H. Y. Kim, M. S. Khil, Y. M. Ra, and D. R. Lee, "Characterization of nano-structured poly( $\varepsilon$-caprolactone) nonwoven mats via electrospinning," Polymer, vol. 44, no. 4, pp. 1287-1294, 2003.

[11] Y. You, B.-M. Min, S. J. Lee, T. S. Lee, and W. H. Park, "In vitro degradation behavior of electrospun polyglycolide, polylactide, and poly(lactide-co-glycolide)," Journal of Applied Polymer Science, vol. 95, no. 2, pp. 193-200, 2005.

[12] J. Hao, M. Yuan, and X. Deng, "Biodegradable and biocompatible nanocomposites of poly(e-caprolactone) with hydroxyapatite nanocrystals: thermal and mechanical properties," Journal of Applied Polymer Science, vol. 86, no. 3, pp. 676-683, 2002.

[13] V. Beachley and X. Wen, "Effect of electrospinning parameters on the nanofiber diameter and length," Materials Science \& Engineering C, vol. 29, no. 3, pp. 663-668, 2009.

[14] Q. P. Pham, U. Sharma, and A. G. Mikos, "Electrospun poly ( $\varepsilon$ caprolactone) microfiber and multilayer nanofiber/microfiber scaffolds: characterization of scaffolds and measurement of cellular infiltration," Biomacromolecules, vol. 7, no. 10, pp. 2796-2805, 2006.

[15] A. Baji, Y. W. Mai, S. C. Wong, M. Abtahi, and P. Chen, "Electrospinning of polymer nanofibers: effects on oriented morphology, structures and tensile properties," Composites Science and Technology, vol. 70, no. 5, pp. 703-718, 2010.

[16] V. N. Malheiro, S. G. Caridade, N. M. Alves, and J. F. Mano, "New poly( $\varepsilon$-caprolactone)/chitosan blend fibers for tissue engineering applications," Acta Biomaterialia, vol. 6, no. 2, pp. 418-428, 2010.

[17] Y. Liu, J.-H. He, J.-Y. Yu, and H.-M. Zeng, "Controlling numbers and sizes of beads in electrospun nanofibers," Polymer International, vol. 57, no. 4, pp. 632-636, 2008.

[18] K. H. Lee, H. Y. Kim, H. J. Bang, Y. H. Jung, and S. G. Lee, "The change of bead morphology formed on electrospun polystyrene fibers," Polymer, vol. 44, no. 14, pp. 4029-4034, 2003.

[19] M. M. Demir, I. Yilgor, E. Yilgor, and B. Erman, "Electrospinning of polyurethane fibers," Polymer, vol. 43, no. 11, pp. 3303-3309, 2002. 

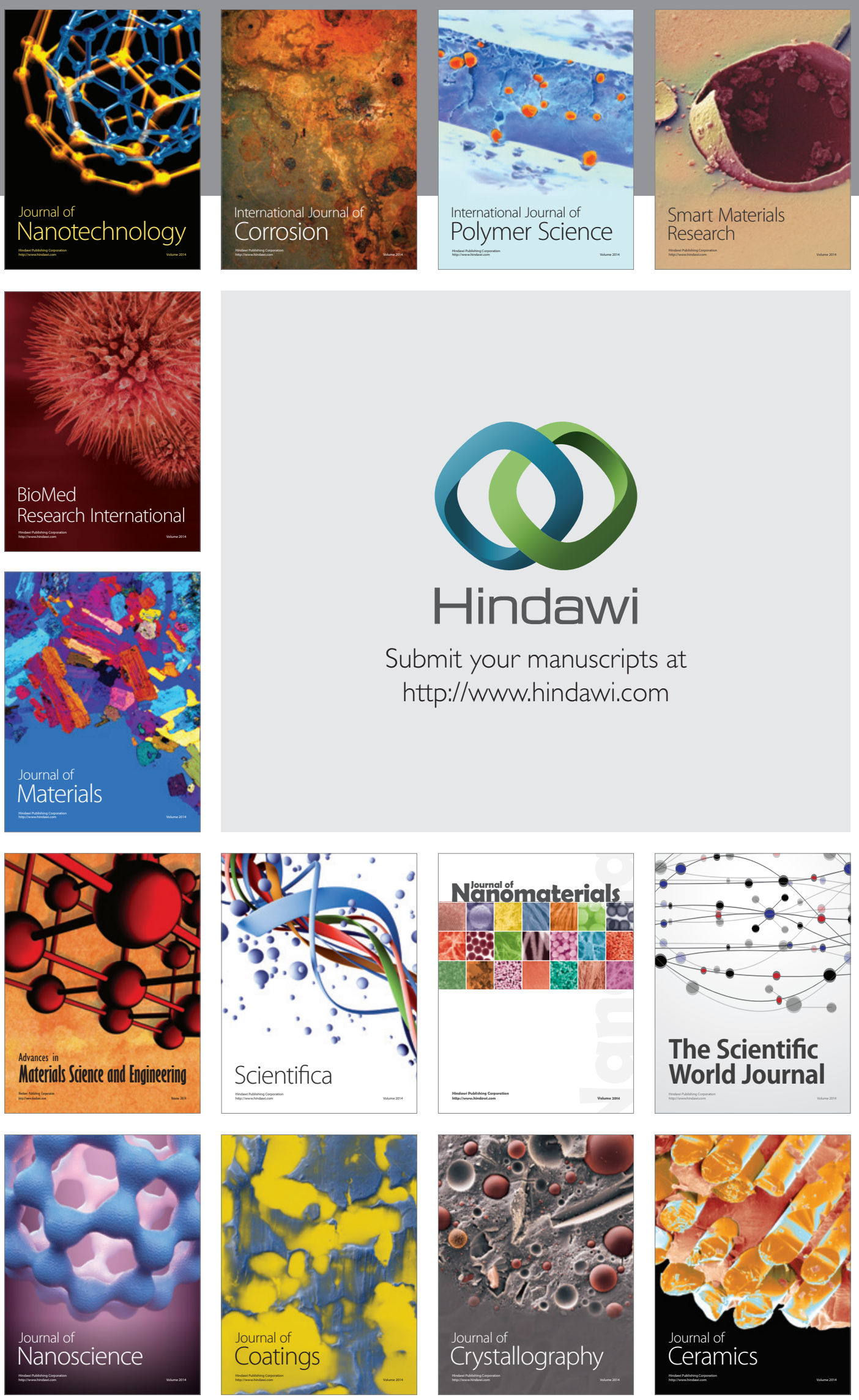

The Scientific World Journal

Submit your manuscripts at

http://www.hindawi.com

\section{World Journal}

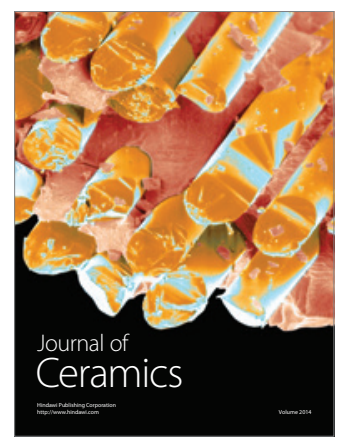

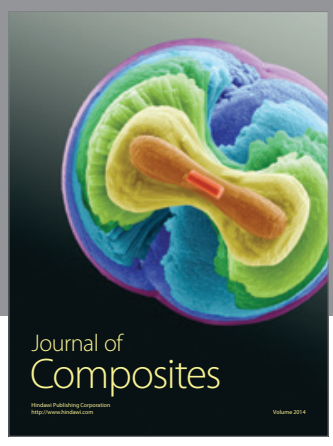
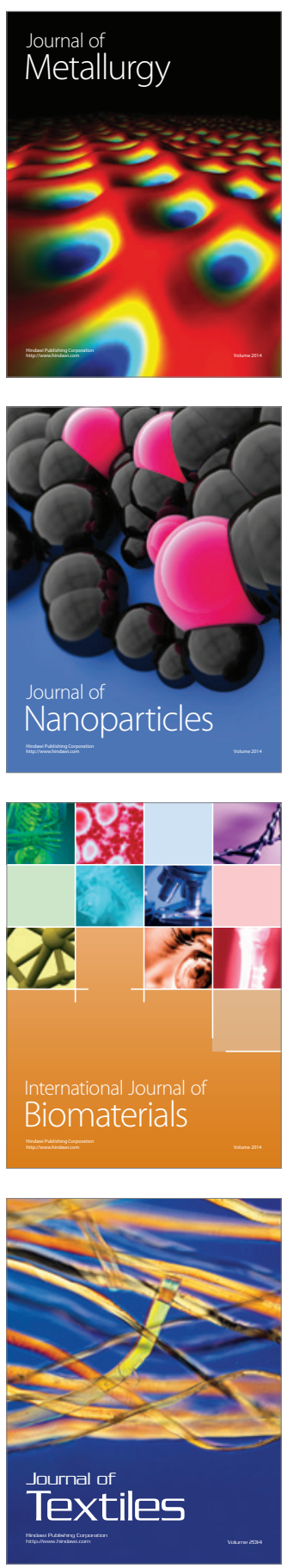